\title{
THE EFFECT OF TELMISARTAN ON COLLAGEN PERCENTAGES BY PICROSIRIUS STAINING IN THE GLOMERULAR RENAL ORGAN OF 8\% NaCl- INDUCED RATS
}

\author{
Khairil Pahmi1 ${ }^{1 *}$, M. Sidratullah², M. Ricky Ramadhian ${ }^{3}$ \\ 1,2Department of Pharmacy, Diploma of Pharmacy, Faculty of Health Science, Universitas Nahdlatul \\ Wathan Mataram, West Nusa Tenggara, Indonesia \\ ${ }^{3}$ Department of Microbiology and Parasitology, Faculty of Medicine, Universitas Lampung, Lampung, \\ Indonesia
}

*Corresponding Author, Email: khairilpahmibiomedis@gmail.com

\begin{abstract}
Exaggerated mineral salt usage is either of the elevated blood pressure and renal organ malady agents, whereas telmisartan is one of a drug that reduces high blood pressure. Telmisartan not only hampers receptors of angiotensin that induce to the alleviating of blood tension, but also drives peroxisome proliferator activated receptor gamma (PPAR- $\gamma$ ) and blocks gene expression of transforming growth factor of beta-1 (TGF $\beta$-1). If telmisartan reduce the collagen percentages in the glomerular renal organ of $8 \% \mathrm{NaCl}$-induced rats were investigated in this research. Twenty five males Wistar 75-90 days of age and 100-150 of body weight rats were utilized in this research. The rats were grouped into five, every group be composed five rats. Group I (KI) as the first negative control did not took $8 \%$ sodium chloride and telmisartan. KII as second negative control took $8 \%$ sodium chloride but not telmisartan. $\mathrm{K} \mathrm{III,} \mathrm{IV} \mathrm{and} \mathrm{V} \mathrm{took} 8 \%$ sodium chloride and telmisartan 3, 6 and $12 \mathrm{mg} / \mathrm{kg} \mathrm{BW}$. The rats were treated every day within 56 days. At the weeks of 8 they were immolated by dislocating their neck and dissected to grab the renal organ. The collagen protein was dyed by picrosirius red staining. Data were displayed as average $\pm S D$. The data were analysed by parametric test (ANOVA and $t$-test) or nonparametric test (Kruskal-Wallis test). A value of $p<0.05$ was considered statistically significant. The outcome indicated that collagen percentages of intraglomerular and extraglomerular renal organ were decrease in telmisartan-medicated Wistar rats group than negative control $(0.05<p<0.05)$. Finally, collagen percentages of intraglomerular and extraglomerular renal organ were lower in $8 \% \mathrm{NaCl}$-treated and telmisartan-medicated male Wistar rats than the group of negative control
\end{abstract}

Copyright (C) 2020 Jsscr. All rights reserved

Keywords: Sodium chloride, Telmisartan, Transforming Growth Factor- $\beta$, Collagen

$\begin{array}{ccc}\text { Received: } & \text { Accepted: } & \text { Online: } \\ \text { 2020-07-4 } & 2020-09-6 & 2020-09-9\end{array}$

\section{Introduction}

Non-infectious disease (NIDs) are the greatest killer within the global that leads 36 million mortalities each year- $6 \%$ of all mortalities worldwide. Twenty five point twenty seven percent $(25.27 \%$ ) or about 9.1 of 36 million NIDs had been premature (previous to 60 (sixty) years). Three principal NIDs (malignancy, cardiovascular and diabetes) and 3 
actions hazard factors (insufficient nutrition, disproportionate bodily tactics, and usage of tobacco and hazardous intake of liqueur [1].

The increase of NIDs predominance such as elevated blood pressure, diabetes mellitus and overweight results in the raise of chronic renal disease surveillance approximately $8 \%$ (8 percent) in step with year. Persistent renal disease is these days the predominant and worldwide well-being troubles which the mechanism of restricting and blocking the development of the final stage of renal illness is still searched. The most important main of the final degree of renal malady is diabetes mellitus $50 \%$, elevated blood pressure $27 \%$, glomerulonephritis 13\% and different cause 10\% [2].

Essential elevated blood pressure is the fundamental community well-being issues. In 2005, approximately a billion society (14\%) worldwide had elevated blood pressure disease. Elevated blood pressure is the main threat aspect for cardiovascular, cerebrovascular and renal maladies that related to the fibrosis illness in some a part of the body, which includes heart, renal organ, liver and cardiovascular $[3,4]$.

The raise of the blood tension specially is led with the aid of many factors. Epidemiologic records show that genetic inside the body, pastime pressure and sphere factor multiplied blood pressure [5], however exaggerated mineral salt like sodium chloride $(\mathrm{NaCl})$ usage is the major factor that drives elevated blood pressure and cardiovascular disease and renal illness worldwide [6]. The mechanism of high blood pressure that drives by way of exaggerated mineral salt is still incomprehensive, however may be related to renal disability to excrete sodium chloride in full-size level [7]. The correlation among exaggerated mineral salt and blood tension continues to be incomplete as well and in reality, that is still denied by means of a few social communities. Recently many researchers attention on the research about the methods of renal destruction by sodium chloride, sympathetic nerve activity (SNA) raised via baroreflex mechanism and collagen accumulation [3].

Based on the previous test on animal, it displayed that $8 \% \mathrm{NaCl}$ improves blood pressure on spontaneously hypertensive rats (SHRs) and normotensive Wistar-Kyoto rats (NWKYs) [8]. The stimulation procedures are envisioned by way of the stimulation of angiotensin II by means of $\mathrm{Na}$ in the path of aldosterone $\rightarrow$ endogenous oabain (EO) [9]. Angiotensin II activates vasoconstriction and drives adrenal gland to produce aldosterone. Hereinafter, aldosterone turns on distal tubulus to reabsorb $\mathrm{Na}$ and $\mathrm{H}_{2} \mathrm{O}$ $[10,11]$. Furthermore, angiotensin II stimulates the convert of fibroblast to miofibroblast through pathway of transforming growth factor-beta1 (TGF- $\beta 1$ ). Miofibroblast synthesizes extracelluer matrix (ECM), hence, ECM piles up inside the tubule interstitial area [12].

Most of antihypertensive medication that largely consumed by society is angiotensin receptor blockers (ARBs), such as telmisartan. Telmisartan not only inhibits angiotensin receptor, however also it can be as agonist partial peroxisome proliferator activated receptor- $\gamma$ (PPAR- $\gamma)$, so as it stimulates PPAR- $\gamma[13,14]$. The activation drives PPAR- $\gamma$ shapes heterodimer with retinoid $X$ receptors (RXRs) so as co-repressor is synthesized that may block TGF- $\beta 1$ expression [15]. 
Based on the argument above, telmisartan treatment to the $8 \%$ sodium chloride-induced rats is most likely expected to be anti-fibrotic by measuring collagen percentages that stained by picrosirius red staining in the glomerular renal organ.

\section{Research Methods}

\subsection{Materials and Method}

25 male Wistar 75-90 days of age and 100-150 gram of body weight rats have been utilized on this research. The rats had been cared within the pen individually, fed pellet, and given consuming water advert libitum. The rats had been positioned inside the room temperature $20-24^{\circ} \mathrm{C}$, the cycle of dark-shiny for 12 hours. Before been given treatment, the rats have been tailored for seven days maximally. The rats were grouped into five, each group be composed 5 rats. Group I (KI) as the first negative manipulate did not take $8 \%$ sodium chloride and telmisartan. KII as second negative manipulate took $8 \%$ sodium chloride but not telmisartan. KIII, IV and $\mathrm{V}$ took $8 \% \mathrm{NaCl}$ and telmisartan 3, 6 and $12 \mathrm{mg} / \mathrm{kg} \mathrm{BW}$. The rats have been treated each day within 56 days. At the weeks of 8 they have been immolated through dislocating their neck and dissected to seize the renal organ. [16-20].

$40 \mathrm{mg}$ telmisartan turned into pounded via mortal and the following add $\mathrm{dH}_{2} \mathrm{O}$ till 40 milliliter. The suspension become taken on via syringe that are suitable to determined rat's dosages. Collagen protein became dyed by using picrosirius red staining. Collagen possibilities were determined by way of calculating the dyed area in 10 field of view. The region dyed become measured by means of imageJ software program as chances of the total region inside an area of view $[8,21,22]$.

\subsection{Statictical Analysis}

Data were displayed as average \pm SD. The facts have been analysed by using parametric test (ANOVA and t-test) or nonparametric test (Kruskal-Wallis test). A price of $\mathrm{p}<0.05$ was considered statistically significant.

\section{Results and Discussion}

The outcome indicated that collagen percentages of intraglomerular and extraglomerular renal organ were lower in telmisartan-medicated Wistar rats group than terrible control $(0.05<p<0.05)$ based on Figure 1 and Table $1 \& 2$.

Table 1. Collagen percentages of intraglomerular (group (K) I and II=negative control, K III, IV and $\mathrm{V}=8 \%$ sodium chloride + telmisartan; 3,6 and $12 \mathrm{mg} / \mathrm{kg}$ of body weight).

\begin{tabular}{|c|c|c|c|c|c|c|c|}
\hline Group (K) & \multicolumn{5}{|c|}{ Collagen percentages (\%) } & Average $\pm S D$ & \multirow{2}{*}{$\frac{\mathrm{p}}{0.01^{*}}$} \\
\hline I & 28.50 & 10.60 & 32.60 & 36.40 & 14.15 & $24.45 \pm 11.40$ & \\
\hline II & 28.90 & 55.60 & 45.90 & 36.80 & 26.20 & $38.68 \pm 12.10^{* *}$ & \\
\hline III & 47.50 & 41.00 & 43.10 & 15.80 & 32.90 & $36.06 \pm 12.50$ & \\
\hline IV & 41.40 & 45.00 & 36.50 & 36.60 & 24.30 & $36.76 \pm 7.80$ & \\
\hline $\mathrm{V}$ & 8.10 & 14.40 & 31.10 & 6.10 & 14.20 & $14.78 \pm 9.80^{* *}$ & \\
\hline
\end{tabular}

**large distinction of suggest in Wistar rat group $(\mathrm{p}<0.05)$

** significant difference of average in Wistar rat K II and K V $(p<0.05)$ 


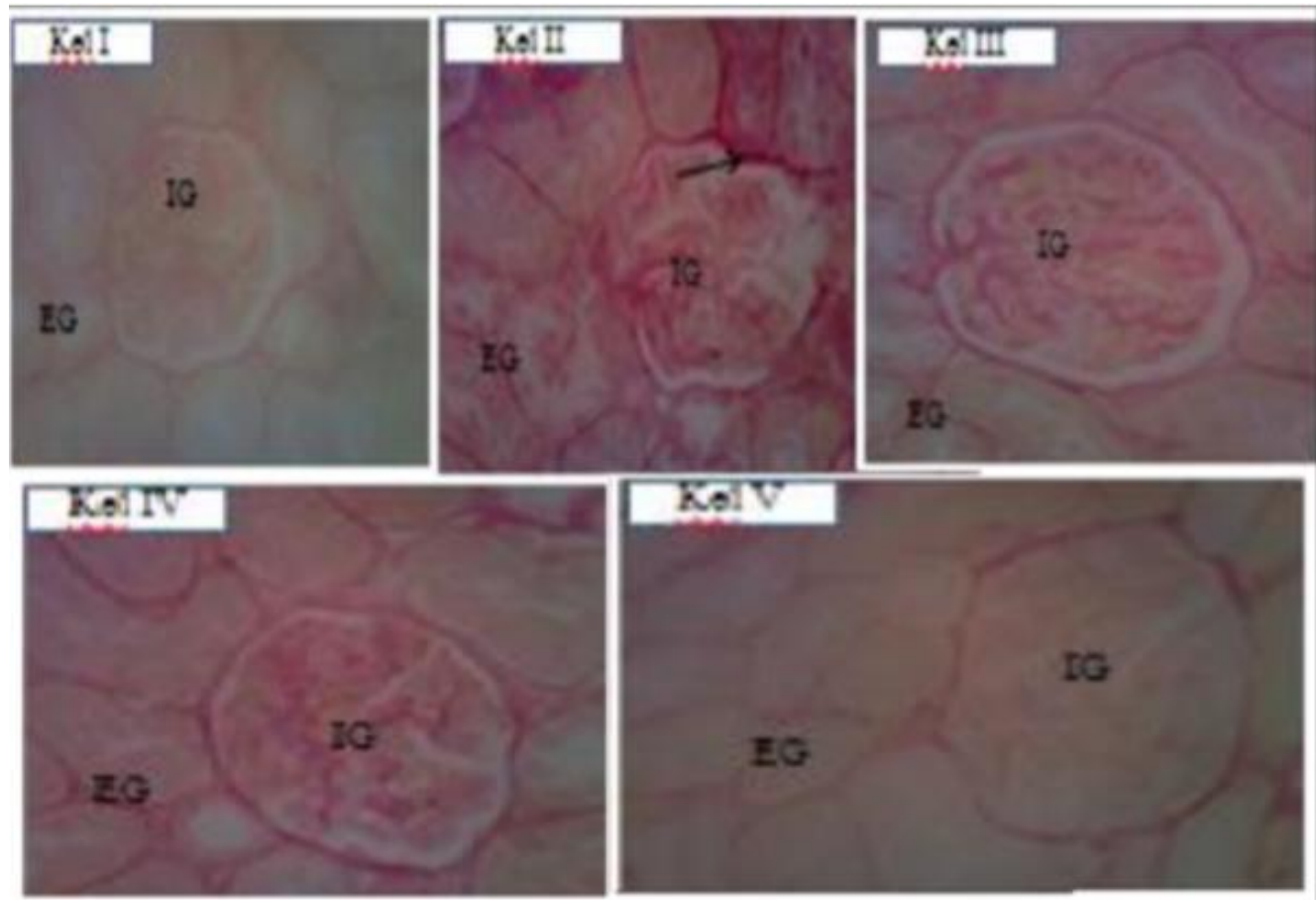

Figure 1. Microscopic image of intraglomerular and extraglomerular renal organ slide in 400x enlargement for group (K) I, II, III, IV and V that have been dyed by way of picrosirius red staining (red color $\rightarrow$ shows collagen). IG: Intraglomerular; EG: Extraglomerular

Table 2. Collagen percentages of extraglomerular (group (K) I and II=terrible control, K III, IV and $\mathrm{V}=8 \%$ sodium chloride + telmisartan; 3,6 and $12 \mathrm{mg} / \mathrm{kg}$ of body weight).

\begin{tabular}{|c|c|c|c|c|c|c|c|}
\hline Group (K) & \multicolumn{5}{|c|}{ Collagen percentages (\%) } & \multirow{2}{*}{$\begin{array}{l}\text { Average } \pm \text { SD } \\
11.72 \pm 6.10\end{array}$} & \multirow{2}{*}{$\frac{\mathrm{p}}{0.059}$} \\
\hline I & 17.60 & 2.83 & 15.10 & 15.10 & 8.00 & & \\
\hline II & 17.70 & 49.80 & 23.20 & 38.90 & 10.40 & $28.00 \pm 16.00$ & \\
\hline III & 15.50 & 23.90 & 21.30 & 9.40 & 19.60 & $17.94 \pm 5.60$ & \\
\hline IV & 23.70 & 16.50 & 26.40 & 28.40 & 19.20 & $22.84 \pm 4.90$ & \\
\hline $\mathrm{V}$ & 15.50 & 10.90 & 22.60 & 5.25 & 17.00 & $14.25 \pm 6.50$ & \\
\hline
\end{tabular}

Cox et al. [4] explained mineral salt is capable of stimulate fibrosis on heart, renal organ and cardiovascular which be researched from two cohort analysis in human population. Hereinafter, Yu et al. [8] expressed mineral salt stimulate fibrosis within the renal organ, ventriculus sinister and myoacardial artery of SHRs and WKYs. The renal organ fibrosis results in the closing degree renal illness that degenerates the renal organ function. The stimulation of fibrosis inside the renal organ increases blood pressure and stimulates continual and acute renal malady.

The raise of TGF- $\beta 1$ feature brought about the increase of renal collagen formation. Based on the preceding test on arterial organ of Wistar rats displayed that $8 \%$ sodium chloride raises the odds of collagen, blood tension, media stiffness, diameter of lumen, 
ratio of media and lumen and percentages of proliferating cellular nuclear antigen (PCNA) expression than control group $(\mathrm{p}<0.05)$. So as, salt-containing diet can raise blood tension and decrease ion pomp action; whereas telmisartan blocks smooth muscle propagation of vascular, collagen deposition and hypertension reduction [23].

Eventually, telmisartan decreases TGF- $\beta 1$ expression, consequently make the reduction of collagen percentages.

\section{Conclusion}

Finally, collagen percentages of intraglomerular and extraglomerular renal organ were decrease in $8 \%$ sodium chloride-induced and telmisartan-medicated male Wistar rats than the items of negative control.

\section{References}

[1]. WHO., 2010, Global status report on non-communicable maladys, Geneva, Switzerland.

[2]. Baltatzi, M.C.H. S., Hatzitolios A., 2011, Role of angiotensin converting enzyme inhibitors and angiotensin receptor blockers in elevated blood pressure of chronic renal organ malady and renoprotection. Hippokratia 15: 2732.

[3]. Blaustein, M.P., et al., 2012, How $\mathrm{NaCl}$ raises blood pressure: A new paradigm for the pathogenesis of saltdependent elevated blood pressure. Am J Physiol Heart Circ Physiol 302: H1031-H1049.

[4]. Cox, N., Pilling, D., Gomer, R.H., 2012, NaCl potentiates human fibrocyte differentiation. PLoS One 7: 1-9.

[5]. Beevers, G., Lip, G.Y.H,, O’Brien, E., 2001, ABC of elevated blood pressure: “The pathophysiology of elevated blood pressure". BMJ 322: 912-916.

[6]. He, F.J., Jenner, K.H., MacGregor, G.A., Avenue, G., 2012, Telmisartan exerts renoprotective actions via peroxisome. Elevated blood pressure 59: 308-316.

[7]. Meneton, P., et al., 2005, Links between dietary salt intake, renal salt handling, blood pressure and cardiovascular maladys. Physiol Rev 86: 679-715.

[8]. Yu, H.C.M, Burrell, L.M., Black, M.J., Wu, L.L., Dilley, R.J., 1998, Salt induces myocardial and renal fibrosis in normotensive and hypertensive rats. Circulation 98: 2621-2628.

[9]. Leenen, F.H.H., 2010, The central role of the brain aldosterone - "ouabain" pathway in salt-sensitive elevated blood pressure. BBA Mol Basis Dis 1802: 11321139.

[10]. Jöhren, O., Dendorfer, A., Dominiak, P., 2004, Cardiovascular and renal function of angiotensin II type-2 receptors. Cardiovasc Res 62: 460-467.

[11]. Starr, C., McMillan, B., 2012, Human Biology. 9th Edn, Brooks/Cole Cengage Learning, Canada.

[12]. Mezzano, S.A., Ruiz-Ortega, M., Egido, J., 2001, Angiotensin II and renal fibrosis. Elevated blood pressure 38: 635638. 
[13]. Chambers, S., Schachter, M., Morrell, J., Gaw, A., Kirby, M., 2008, Telmisartan an effective anti-hypertensive for $24 \mathrm{~h}$ blood pressure control. Drugs in Context 4: 1-14.

[14]. Funao, K., et al., 2009, Telmisartan as a peroxisome proliferatoractivated receptor Á ligand is a new target in the treatment of human renal cell carcinoma. Mol Med Rep 2: 193-198.

[15]. Rotman, N., Wahli, W., 2010, PPAR modulation of kinase-linked receptor signaling in physiology and malady. Physiology 25: 176-185.

[16]. Xu, L., \& Liu, Y., 2013, Administration of telmisartan reduced systolic blood pressure and oxidative stress probably through the activation of PI3K/Akt/eNOS pathway and NO release in spontaneously hypertensive rats. Physiol Res 62: 351359.

[17]. Younis, F., Stern, N., Limor, R., Oron, Y., Zangen, S., 2010, Telmisartan ameliorates hyperglycemia and metabolic profile in non-obese Cohen-Rosenthal diabetic hypertensive rats via peroxisome proliferator activator receptor- $\gamma$ activation. Metabolism 59: 1200-1209.

[18]. Matsumura, T., et al., 2011, Telmisartan exerts antiatherosclerotic effects by activating in macrophages. Arterioscler Thromb Vasc Biol 31: 1268-1275.

[19]. Liu, W., Wang, W., Song, S.W., Gu, X.F., Ma, X.J., 2011, Synergism of telmisartan and amlodipine on blood pressure reduction and cardiorenal protection in hypertensive rats. J Cardiovasc Pharmacol 57: 308-316.

[20]. Jawi, I.M., Yasa, I.W.P.S., Suprapta, D.N., Mahendra, A.N., 2012, Antihypertensive effect and eNOS expressions in $\mathrm{NaCl}$-induced hypertensive rats treated with purple sweet potato. Univ J Med Dent 1: 102-107.

[21]. Lync, M.J., Raphael, S.S., Mellor, L.D., Spare, P.D., Inwood MJH, et al., 1969, Medical Laboratory Technology and Clinical Pathology. W.B. Saunders Company, United States of America (USA).

[22]. Fatchiyah, A.E.L., Widyarti, S., Rahayu, S., 2011, Biologi Molekuler "Prinsip Dasar Analisis". Erlangga, Jakarta.

[23]. Shang, Q.H., Min, X.Q., Liu, C., Mao, W.H., Shang, Q.H., 2012, Effects of high salt diet on arterial remodelling and the intervention of tel 